\section{Comentario sobre el texto "Tuberculosis" de Victorino Farga y José Antonio Caminero $3^{a}$ Edición. 2011 Editorial Mediterráneo}

En sus casi 500 páginas, cubre todos los aspectos importantes relacionados con la tuberculosis humana. La mayor extensión del texto, comparado con anteriores ediciones, se debe al enorme volumen de nuevas informaciones.

Con estilo claro, sencillo, didáctico, hace una excelente presentación de la epidemiología, etiopatogenia, clínica, manejo operacional y otros temas de la enfermedad.

La información presentada, se basa en el conocimiento científicamente establecido, en la conceptualización fundamental y la evidente experiencia clínica y juicio ponderado de los autores.

En especial los temas sobre diagnóstico y tratamiento, son expuestos en forma completa, actualizada e incluso proyectada a futuro, de acuerdo a la última información disponible. El complejo problema del tratamiento de la multidrogo-resistencia (MDR), se presenta desde su prevención, con el adecuado tratamiento de los casos nuevos, hasta el difícil manejo de los enfermos que presentan enfermedad causada por cepas bacilares con resistencia ampliada (TB-XDR). También tiene su espacio el tratamiento de las micobacteriosis, tema no siempre presentado en este tipo de textos.

Es satisfactorio observar la importancia dada a la presentación del Programa Nacional de Control de la Tuberculosis, presentando sus conceptos fundamentales y aunque algunos de ellos son discutibles, avanzando planteamientos sobre la necesaria evolución del Programa de Control de la Tuberculosis. $\mathrm{Al}$ respecto, se debe destacar el valor de señalar que, en ningún caso la solución de este problema de Salud Pública, debe ser entregado al manejo privado de casos clínicos que demandan atención, sin que ello signifique desconocer la posibilidad de colaboración públicoprivada en aspectos específicos de colaboración para el éxito del Programa.

Aunque la obra es conceptual y temáticamente exhaustiva, considerando temas como la coinfección VIH/Tuberculosis, micobacteriosis, Tuberculosis en niños, localizaciones extra pulmonares, bioseguridad, poblaciones vulnerables etc, logra hacerlo en forma sintética, sin recargar su redacción con detalles innecesarios.

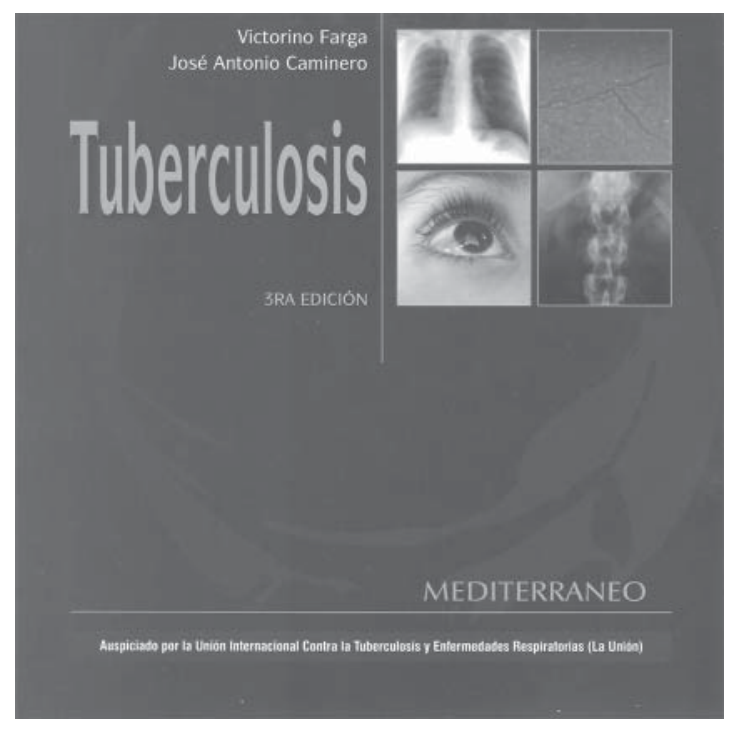

Hace algunos años, un estudio de la OPS, sobre enseñanza de la Tuberculosis en Escuelas de Medicina en América Latina, demostró que las primeras ediciones de "Tuberculosis" de Farga, era uno de los textos más apreciados y utilizados en esas escuelas. He solicitado en la Oficina del Programa de Libros de Textos, (PALTEX), de la Representación OPS en Chile, que se adquieran ejemplares de esta $3^{\text {a }}$ edición para ponerlos a disposición de estudiantes de medicina y médicos de la Región.

Finalmente, quiero expresar que conozco a Victorino Farga desde nuestros años de estudiantes, luego tuve la oportunidad de ser su colaborador en el Hospital San Juan de Dios, cuyo Centro de Enfermedades Broncopulmonares, marcó rumbos en el Control de la Tuberculosis en Chile y luego a lo largo de mi vida profesional, he tenido muchas veces la oportunidad de compartir con él, nuestro común interés en lograr el control de la tuberculosis y su eliminación como problema de Salud Pública. Para mí, esta obra, es la evidente demostración, una vez más, de su categoría intelectual, insaciable sed de conocimientos sobre esta materia, generosa calidad docente y sostenido apasionamiento sobre el tema.

Dr. Álvaro Yánez del Villar Ex Encargado Nacional del Programa de Control de la Tuberculosis/Chile

Ex Asesor Regional OPS/OMS del Programa de Control de la Tuberculosis 